\title{
CORRIGENDUM \\ Energy expenditure in people with motor-complete paraplegia
}

\author{
T Holmlund, E Ekblom-Bak, E Franzén, C Hultling, L Nilsson Wikmar and K Wahman
}

Spinal Cord (2017) 55, 796-797; doi:10.1038/sc.2017.68

Correction to: Spinal Cord (2017) 55, 774-781; published online 4 April 2017

Since the publication of this article, the authors have noticed an error in Table 3. The correct table can be seen below. As a result, there is also a slight amendment to the discussion.
Where it says 'This is comparable with $1 \mathrm{~h}$ of wheeling outdoors at exercise pace $\left(8 \mathrm{~km} \mathrm{~h}^{-1}\right)$.' it should now say 'This is comparable with $30 \mathrm{~min}$ of wheeling outdoors at exercise pace $\left(8 \mathrm{~km} \mathrm{~h}^{-1}\right)$.'

The authors apologise for any inconvenience caused by this error. 


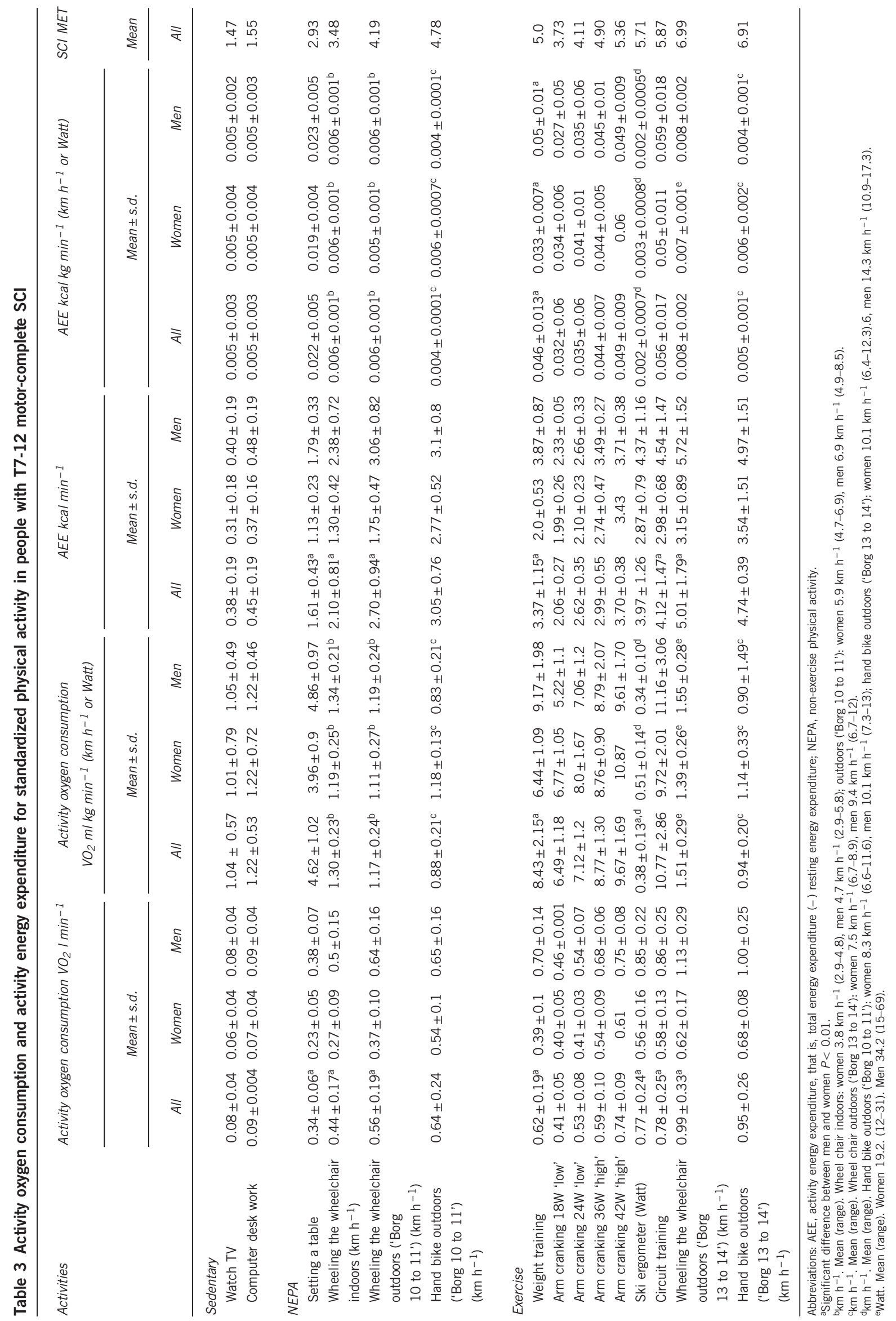

